\title{
Exploring nutrition literacy: Attention to assessment and the skills clients need
}

\author{
Heather Gibbs ${ }^{1,2}$, Karen Chapman-Novakofski ${ }^{*}$ \\ ${ }^{1}$ Department of Family \& Consumer Sciences, Olivet Nazarene University, Bourbonnais, USA \\ ${ }^{2}$ Department of Food Science and Human Nutrition, University of Illinois, Urbana, USA; \\ *Corresponding Author: kmc@illinois.edu
}

Received 3 December 2011; revised 11 January 2012; accepted 18 January 2012

\begin{abstract}
This exploratory study examines nutrition literacy in two parts: 1) the level of attention to health literacy among nutrition professionals, and 2) the nutrition professional's perspective of skills/ knowledge needed to understand nutrition education. Part 1 included an online survey in which RD participants $(n=206)$, recruited from three dietetic practice groups, identified use of health literacy assessments during client education. Most participants $\mathbf{( 7 9 \% )}$ did not use a validated health literacy assessment. There was a significant difference in response to having written materials for different health literacy levels depending on time spent providing nutrition education, with those sending less time in education responding they more often had more materials (Chi-square 8.6, $p=0.035$ ) and depending on job description, public health more often than outpatient dietitian $(p=0.006)$. Part 2 utilized key informant interviews $(n=8)$, administered by telephone. Content analysis revealed a significant theme among answers that the skills required for understanding diet education is dependent on the type of diet instruction provided, with diabetes frequently noted as a disease requiring greater knowledge and skills. Nutrition educators need an instrument to assess client nutrition literacy. Potential instruments should assess skills related to portion size estimation, macronutrient knowledge, interpretation of food labels, and food grouping.
\end{abstract}

Keywords: Nutrition; Literacy; Education; Counseling Skills

\section{INTRODUCTION}

Education is vitally important for successful health outcomes, but information that is not understood by the client is futile and potentially harmful. Health literacy has been defined as "the degree to which individuals have the capacity to obtain, process, and understand basic health information and services needed to make appropriate health decisions" [1].

The 2003 National Assessment of Adult Literacy incurporated health literacy, measuring participant performance on 28 tasks. Only $12 \%$ of those surveyed had proficient health literacy, with $14 \%$ of participants who had below basic health literacy skills and 22\% of participants had basic health literacy skills [2].

Clearly, nutrition is one important sector of health care where education is needed. A $68 \%$ overweight/obesity rate [3] suggests inadequacy in knowledge, motivation, and/or resources. A healthy diet plays an important role in overweight/obesity prevention as well as prevention of subsequent health conditions. However, understanding what comprises a healthful diet is complex and may require high cognitive skills.

Because there is little discussion of health literacy within the nutrition literature, the aims of this study were to examine the level of attention to health literacy among nutrition professionals and to identify the skills/knowledge necessary for understanding nutrition education as perceived by nutrition professionals.

\section{METHODS}

\subsection{Attention to Health Literacy among Nutrition Professionals (Survey)}

A survey was performed to gather formative data pertaining to the extent of assessment that nutrition professionals were conducting prior to providing nutrition education (Survey Monkey ${ }^{\circ}$ ).

All methods were approved by the Institutional Review Board (IRB). Three Dietetic Practice Groups (DPGs) of the American Dietetic Association (ADA) were selected (estimated $n=3251$ members) because the natures of their practice areas involve nutrition education, and participants were recruited by email. 
To test the hypothesis that spending more of job time in nutrition education results in more attention to issues of health literacy, respondents were classified based on their estimate of nutrition education job as follows: $80 \%$ or more (almost all); 50\% - 80\% (majority); 20\% - 50\% (some); or less than $20 \%$ (minimal). Descriptive and comparative analyses were completed using SPSS (version 11.01, Chicago, IL 2001).

\subsection{Targeted Interviews Concerning Health Literacy}

We conducted a second study of nutrition professsionals using the "interview guide approach" [4] for key informant interviews. Our objective was to determine what basic skills are needed to understand nutrition/diet education. Our hypothesis was that nutrition professionals would identify components of nutrition literacy not included in general health literacy assessments. All methods were approved by the IRB.

A recruiting email was distributed to 59 nutrition professionals with related research interests and/or nutrition education experience. Those who agreed to interviews (n $=8$ ) were sent a consent document and interview questions to review before the scheduled interview. Telephone interviews were audio-recorded for the purpose of improved transcription accuracy. The guided interview contained 10 questions, six focusing on ideas and ex- perience with nutrition literacy and four were demographic in nature. Data were evaluated using content analysis [5], identifying important examples, themes, and patterns in the data.

\section{RESULTS}

\subsection{Survey}

Participation ( $\mathrm{n}=206$ ) varied between questions, as can be seen in Table 1. In a one-way ANOVA comparison using the classification variable, Job time spent in nutrition education, a significant difference was found for the dependent variable, Availability of written materials for different levels of understanding $(\mathrm{P}=0.025)$. Post hoc testing (Kruskal-Wallis) indicated a significant difference between those identifying spending $>80 \%$ of job time and those spending 50 to $80 \%$ of job time in nutrition education more often replied they never, occasionally or sometimes had written material available for different levels whereas those spending 20 to $50 \%$ and $<20 \%$ of job time in nutrition education more often they usually or always had different materials $(P=0.035)$.

A significant difference was also found for two dependent variables: Availability of written materials for different levels of understanding $(\mathrm{P}=0.006)$ and Adjusts education methods based on perceived understanding $(\mathrm{P}=$ 0.007 ) with Job description as the classification variable.

Table 1. Response summary, selected questions.

\begin{tabular}{|c|c|c|c|c|c|c|}
\hline \multirow[b]{2}{*}{ Question } & \multicolumn{6}{|c|}{ Answering Options, percentage, (n) } \\
\hline & Always & Usually & Sometimes & Occasionally & Never & $\begin{array}{l}\text { Response } \\
\text { Count }\end{array}$ \\
\hline $\begin{array}{l}\text { In my practice, an objective health literacy } \\
\text { assessment is conducted with clients/ patients. }\end{array}$ & $\begin{array}{l}11.5 \% \\
(n=6)\end{array}$ & $\begin{array}{l}14.4 \% \\
(n=20)\end{array}$ & $\begin{array}{l}12.2 \% \\
(\mathrm{n}=17)\end{array}$ & $\begin{array}{c}9.4 \% \\
(n=13)\end{array}$ & $\begin{array}{l}52.5 \% \\
(n=73)\end{array}$ & 139 \\
\hline $\begin{array}{l}\text { In my practice, a subjective health literacy } \\
\text { assessment is conducted with clients/ patients. }\end{array}$ & $\begin{array}{l}27.0 \% \\
(n=37)\end{array}$ & $\begin{array}{l}24.1 \% \\
(n=33)\end{array}$ & $\begin{array}{l}17.5 \% \\
(n=24)\end{array}$ & $\begin{array}{c}8.0 \% \\
(n=11)\end{array}$ & $\begin{array}{l}23.4 \% \\
(\mathrm{n}=32)\end{array}$ & 137 \\
\hline I chart/document an assessment of health literacy. & $\begin{array}{l}14.7 \% \\
(n=20)\end{array}$ & $\begin{array}{l}19.9 \% \\
(n=27)\end{array}$ & $\begin{array}{c}8.8 \% \\
(n=12)\end{array}$ & $\begin{array}{l}16.2 \% \\
(n=22)\end{array}$ & $\begin{array}{l}40.4 \% \\
(n=55)\end{array}$ & 136 \\
\hline $\begin{array}{l}\text { I use methods other than health literacy } \\
\text { assessment tools to identify levels of } \\
\text { understanding in my clients/patients. }\end{array}$ & $\begin{array}{l}21.6 \% \\
(n=27)\end{array}$ & $\begin{array}{l}29.6 \% \\
(n=37)\end{array}$ & $\begin{array}{l}20.0 \% \\
(n=25)\end{array}$ & $\begin{array}{l}12.8 \% \\
(\mathrm{n}=16)\end{array}$ & $\begin{array}{l}16.0 \% \\
(n=20)\end{array}$ & 125 \\
\hline $\begin{array}{l}\text { I have written materials available to meet } \\
\text { different levels of understanding. }\end{array}$ & $\begin{array}{l}21.3 \% \\
(n=26)\end{array}$ & $\begin{array}{l}33.6 \% \\
(n=41)\end{array}$ & $\begin{array}{l}25.4 \% \\
(\mathrm{n}=31)\end{array}$ & $\begin{array}{l}12.3 \% \\
(n=15)\end{array}$ & $\begin{array}{l}7.4 \% \\
(\mathrm{n}=9)\end{array}$ & 122 \\
\hline \multirow[t]{2}{*}{$\begin{array}{l}\text { I adjust my education methods based on } \\
\text { what I perceive or have assessed the } \\
\text { client/patients level of understanding to be. }\end{array}$} & $\begin{array}{l}70.2 \% \\
(\mathrm{n}=87)\end{array}$ & $\begin{array}{l}25.8 \% \\
(\mathrm{n}=32)\end{array}$ & $\begin{array}{l}3.2 \% \\
(\mathrm{n}=4)\end{array}$ & $\begin{array}{l}0.8 \% \\
(\mathrm{n}=1)\end{array}$ & $\begin{array}{c}0.0 \% \\
(\mathrm{n}=0)\end{array}$ & 124 \\
\hline & REALM & TOFHLA & NVS & Other & None & Response Count \\
\hline \multirow[t]{2}{*}{$\begin{array}{l}\text { Which of the following health literacy } \\
\text { assessments do you or your practice use? }\end{array}$} & $\begin{array}{c}2.4 \% \\
(n=3)\end{array}$ & $\begin{array}{l}0.8 \% \\
(\mathrm{n}=1)\end{array}$ & $\begin{array}{c}2.4 \% \\
(n=3)\end{array}$ & $\begin{array}{l}15.2 \% \\
(n=19)\end{array}$ & $\begin{array}{l}79.2 \% \\
(n=99)\end{array}$ & 125 \\
\hline & $\begin{array}{l}\text { Year completed } \\
\text { in school }\end{array}$ & \multicolumn{2}{|c|}{$\begin{array}{l}\text { Notes in medical } \\
\text { record }\end{array}$} & $\begin{array}{l}\text { Indicators of } \\
\text { reading problems }\end{array}$ & Other & Response Count \\
\hline $\begin{array}{l}\text { Which of the following methods do you use } \\
\text { to identify levels of understanding in your } \\
\text { clients/patients? (May answer more than one.) }\end{array}$ & $\begin{array}{c}49.1 \% \\
(n=54)\end{array}$ & \multicolumn{2}{|c|}{$\begin{array}{l}38.2 \% \\
(n=42)\end{array}$} & $\begin{array}{c}87.3 \% \\
(n=96)\end{array}$ & $\begin{array}{c}38.2 \% \\
(n=42)\end{array}$ & 110 \\
\hline
\end{tabular}


Public health nutritionists had materials more often than outpatient dietitians.

Most significantly, the mode for question five indicated that of 125 participants, regardless of time spent in nutrition education, 99 (79.2\%) did not use validated health literacy assessments when working with their clients.

\subsection{Targeted Interviews}

Participants $(n=8)$ indicated an average of 27 years (range 11 - 40 years) experience in the field of nutrition; seven were registered dietitians; all have graduate degrees in nutrition-related fields (Ph.D., $\mathrm{n}=4$ ); six indicated their jobs involve a combination of nutrition related research, education, and outreach.

A significant theme among answers was that the skills required for understanding diet education were dependent on the type of diet instruction provided, with diabetes frequently noted as a disease requiring greater knowledge and skills. Conceptual skills for macronutrients were important with diabetes $(\mathrm{n}=5)$, as well as basic math (n $=4$ yes; 2 = depends) and portion sizes ( $\mathrm{n}=4$ yes; $2=$ depends). Knowledge of MyPyramid/food groups yielded mixed results $(\mathrm{n}=3$ yes; $2=$ depends, $2=$ no, $1=$ no response). In addition, four indicated that all prompted components (macronutrient knowledge, food group knowledge, basic math skills, and competency with household measurements) were important. Unprompted comments indicated that diet and disease/health concepts were important ( $n=4)$ as well as food composition/ingredients knowledge $(n=3)$.

Key informants frequently addressed the need for certain skills in some diseases but not in others. With this idea in mind and with consideration of time constraints for nutrition educators, we developed a nutrition literacy assessment algorithm (Table 2) for determining if clients need macronutrient knowledge; numeracy skills for label reading; household measurement skills; or food group identification skills. In this way, only the skills that are needed to understand the anticipated education are evaluated.

\section{DISCUSSION}

\subsection{Survey}

This preliminary research indicates that many nutrition educators are not conducting health literacy screening. It may be that current health literacy assessment instruments are inadequate for nutrition professionals because they do not identify a person's nutrition literacy, only print literacy using health-related words and phrases.

Validated instruments for assessment, such as the Rapid Estimate of Adult Literacy in Medicine (REALM) [6], the Test of Functional Health Literacy in Adults (TOFHLA) [7] and the Short Test of Functional Health Literacy in Adults (S-TOFHLA) [8] only evaluate print literacy and/or numeracy using words and concepts within health care. With relationship to nutrition, two instruments have surfaced, the Newest Vital Sign (NVS) and the Nutrition Literacy Scale (NLS). The NVS [9] has been validated as assessing both print literacy and numeracy, but no questions seek to identify nutrition knowledge. Diamond [10] published validation results of his NLS, but the instrument itself was not published, and it is unclear whether this instrument provides any measures beyond print literacy.

\subsection{Targeted Interviews}

It was clear in our research nutrition educators find a tiered effect of skills needed to understand nutrition education. In general, if a disease with nutrition implication is present, the need for nutrition and food-related skills increase, whereas many felt anyone with interest can learn something about nutrition, however small, with minimal skills. It is, therefore, not surprising that

Table 2. Nutrition literacy assessment algorithm.

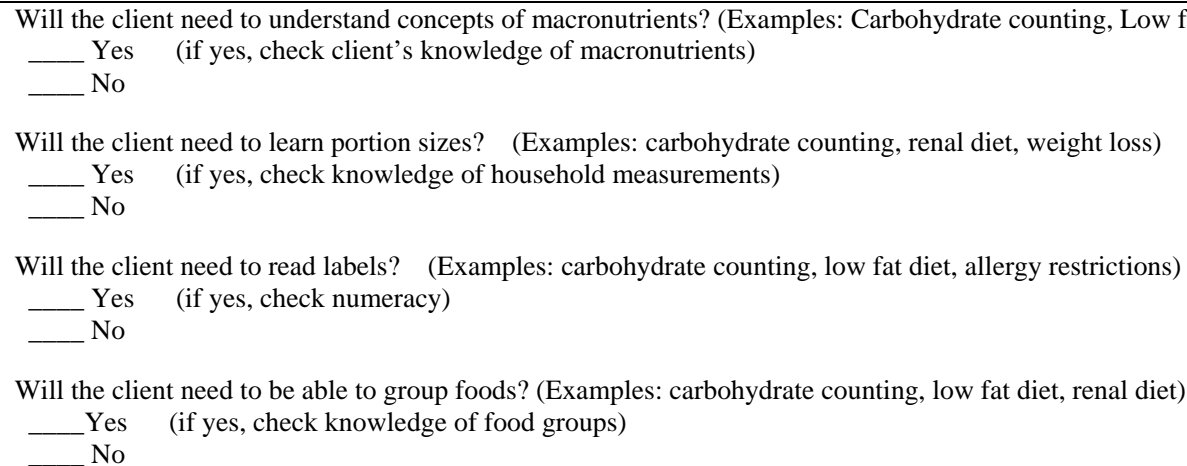

A nutrition professional can use this algorithm to determine which components of nutrition literacy assessment to evaluate based on the type of diet instruction that is required. To check a client's knowledge of macronutrients, 6 questions were developed. To check a client's knowledge of portion sizes, 6 questions were developed. To check a client's understanding of food labels, 6 questions were developed. To assess a client's understanding of food groups, they are asked to place 16 foods in the correct food group. 
diabetes was often mentioned by participants as a disease requiring greater knowledge and skill in nutrition. Reduced health literacy is common in those with diabetes [11] and is associated with poorer glycemic control [12] and increased episodes of hypoglycemia [13]. For effective blood sugar management, the American Diabetes Association recommends medical nutrition therapy for those with diabetes to include monitoring of fat and carbohydrate intake, and attention to overall energy intake for those who need to lose weight [14]. Further, because of the likelihood of comorbidities, those with diabetes should often be concerned about other nutrient intakes as well, such as saturated and trans fat, sodium, and cholesterol [15]. Other diseases with relationship to nutrition that have implications for reduced health literacy include hypertension [16] and infant and child feeding practices [17], and, although research is not yet available, there is also growing interest in the chronic kidney disease population [18].

Although the number of survey participants in part 1 of the study was only $6.3 \%$ of the total, the DPG listserve organizers indicated it is expected that 25\% - 30\% of email recipients (781 - 975 people) would have opened the email invitation (personal communication, two DPG webmasters). With this as the survey sample, $26 \%$ completed the first question of the survey, with varied participation in other questions. As such, participation reached the expectation of 25\% [19]. Likewise, the small number of participants in part 2 of this research is a noted limitation. However, the participants each speak from years of experience in nutrition education, which strengthens the credibility of the data. In addition, it was determined with these participants that we achieved saturation of response.

\section{PRACTICAL IMPLICATIONS}

Regardless of the disease state, potential exists in any patient or client education encounter for reduced health literacy. While counseling skills are important [20], having tools to use in those counseling sessions is equally important. While most literacy research focuses on print material adaptation [21], knowing topics that need to be covered is essential. However, without an instrument that specifically addresses nutrition, nutrition professionals are limited to identifying problems with print literacy and numeracy, which may not provide enough information in regard to skills in measuring portion sizes, understanding macronutrients, or food groups. Our algorithm allows nutrition professionals to choose assessments based on the skill needed for understanding the nutrition education to follow.

\section{REFERENCES}

[1] Neilson-Bowman, L. (2004) Health literacy: A prescription to end confusion. Institute of Medicine, National
Academies Press, Washington DC.

[2] U.S. Department of Education (2006) The health literacy of America's adults: Results from the 2003 national assessment of adult literacy. http://nces.ed.gov/naal/

[3] Flegal, F.M., Carroll, M.D., Ogden C.L. and Curtin, L.R. (2010) Prevalence and trends in obesity among US adults, 1999-2008. Journal of the American Medical Association, 303, 235-241. doi:10.1001/jama.2010.518

[4] Patton, M.Q. (1990) Qualitative evaluation and research methods. Second Edition, Sage, Newbury Park.

[5] Patton, M.Q. (1987) How to use qualitative methods in evaluation. Sage, Newbury Park.

[6] Davis, T.C., Long, S.W., Jackson, R.H., Mayeaux, E.J., George, R.B., Murphy, P.W. and Crouch, M.A. (1993) Rapid estimate of adult literacy in medicine: A shortened screening instrument. Family Medicine, 25, 391-395.

[7] Parker, R.M., Baker, D.W., Williams, M.V. and Nurss, J.R. (1995) The test of functional health literacy in adults: A new instrument for measuring patients' literacy skills. Journal of General International Medicine, 10, 537-541. doi:10.1007/BF02640361

[8] Baker, D.W., Williams, M.V., Parker, R.M., Gazamararian, J.A. and Nurss, J.R. (1999) Development of a brief test to measure functional health literacy. Patient Education and Counseling, 38, 33-42. doi:10.1016/S0738-3991(98)00116-5

[9] Weiss, B.D., Mays, M.Z., Martz, W., Castro, K.M., DeWalt, D.A., Pignone, M.P., Mockbee, J. and Hale, F.A. (2005) Quick assessment of literacy in primary care: The newest vital sign. Annals of Family Medicine, 3, 514-522. doi:10.1370/afm.405

[10] Diamond, J.J. (2007) Development of a reliable and construct valid measure of nutritional literacy in adults. $\mathrm{Nu}$ trition Journal, 6, 5. http://www.nutritionj.com/content/pdf/1475-2891-6-

[11] Williams, M.V., Baker, D.W., Parker, R.M. and Nurss, J.D. (1998) Relationship of functional health literacy to patients' knowledge of their chronic disease. Archives of Intern Medicine, 158, 166-172. doi:10.1001/archinte.158.2.166

[12] Schillinger, D., Grumbach, K., Piette, J., Wang, F., Osmond, D., Daher, C., Palacios, J., Sullivan, G.D. and Bindman, A.B. (2002) Association of health literacy with diabetes outcomes. Journal of the American Medical Association, 288, 475-482. doi:10.1001/jama.288.4.475

[13] Sarkar, U., Karter, A.J., Liu, J.Y., Moffet, H., Adler, N.E. and Schillinger, D. (2010) Hypoglycemia is more common among type 2 diabetes patients with limited health literacy: The diabetes study of northern California (DISTANCE). Journal of General Internal Medicine, 25, 962968. doi:10.1007/s11606-010-1420-z

[14] American Diabetes Association (2010) Standards of medical care in diabetes 2010. Diabetes Care, 33, S11S61.

[15] American Diabetes Association (2008) Nutrition recommendations and interventions for diabetes. Diabetes Care, 31, S61-78. doi:10.2337/dc08-S061

[16] Pandit, A.U., Tang, J.W., Bailey, S.C., Davis, T.C., Boc- 
chini, M.V., Persell, S.D., Federman, A.D. and Wolf, M.S. (2009) Education, literacy, and health: Mediating effects on hypertension knowledge and control. Patient Education and Counseling, 75, 381-385. doi:10.1016/j.pec.2009.04.006

[17] Sanders, L.M., Shaw, J.S., Guez, G., Baur, C. and Rudd, R. (2009) Health literacy and child health promotion: Implications for research, clinical care and public policy. Pediatrics, 124, S306-S314. doi:10.1542/peds.2009-1162G

[18] Devrag, R. and Gordon, E.J. (2009) Health literacy and kidney disease: Toward a new line of research. American Journal of Kidney Disease, 53, 884-889. doi:10.1053/j.ajkd.2008.12.028

[19] Cook, C., Heath, F. and Thompson, R.L. (2000) A meta- analysis of response rates in web- or internet-based surveys. Educational and Psychological Measurement, 60, 821-836. doi:10.1177/00131640021970934

[20] Marley, S.C., Carbonneau, K., Lockner, D., Kibbe, D. and Trowbridge, F. (2011) Motivational interviewing skills are positively associated with nutritionist self-efficacy. Journal of Nutrition Education and Behaviour, 43, 28-34. doi:10.1016/j.jneb.2009.10.009

[21] Townsend, M.S., Sylva, K., Martin, A., Metz, D. and Wooten-Swanson, P. (2008) Improving readability of an evaluation tool for low-income clients using visual information processing theories. Journal of Nutrition Education and Behaviour, 40, 181-186.

doi:10.1016/j.jneb.2007.06.011 